\title{
Comparative effects of different fractions of crude aqueous extract of Ficus exasperata leaves on blood pressure
}

\author{
*Augustin Kouao Amonkan¹, André Brou Konan¹, Léandre Kouakou Kouakou², Mathieu Nahounou Bleyere², \\ Marcel Guy Kouamé Bouafou ${ }^{3}$, Séraphin Kati-Coulibaly ${ }^{1}$ \\ ${ }^{1}$ Laboratory of Nutrition and Pharmacology, UFR-Biosciences, Felix Houphouët-Boigny University, 22 BP 582 Abidjan 22, Abidjan, Côte d'Ivoire \\ ${ }^{2}$ Laboratory of Physiology Pharmacology and Phytotherapy, UFR Sciences de la Nature, Nangui Abrogoua University, 02 BP 801 Abidjan 02, Abidjan, Côte d'Ivoire \\ ${ }^{3}$ Division of Life and Earth Sciences, Department of Sciences and Technology, Ecole Normale Superieure (ENS), 25 BP 663 Abidjan 25, Abidjan, Côte d'Ivoire
}

\begin{abstract}
Ficus exasperata has been extensively used in folk medicine for the treatment of many ailments. The aqueous extract of leaves of this herb reduced blood pressure through its cholinomimetic effect. In this study, different fractions of the crude extract of $F$. exasperata leaves (FEFIX) were evaluated on blood pressure. Fractionated extracts were obtained by successive use of different solvents on the total crude extract. Phytochemical analysis was performed for each fraction and increasing doses $(0.25$ to $40 \mathrm{mg} / \mathrm{kg}$ b.w. $) \mathrm{were}$ administered intravenously. The phytochemical screening showed that alkaloids and phenols were found in ethanol fraction (FEFEFIX) and methanol fraction (FM-FEFIX). Saponins and tannins have been identified only in the aqueous fraction (FA-FEFIX). Decreases in blood pressure were $40.02 \pm 3.08 \mathrm{~mm} \mathrm{Hg}$ for the ethanol fraction (FE-FEFIX), $9.95 \pm 2.09 \mathrm{~mm} \mathrm{Hg}$ for the methanol fraction (FM-FEFIX) and $5.26 \pm 1.46 \mathrm{~mm} \mathrm{Hg}$ in the aqueous fraction (FA-FEFIX). Hypotension induced by ethanol fraction is found to be greater than those induced by the other two fractions. In conclusion, this study showed that the hypotensive effect of $F$. exasperata leaves was greater with its ethanol extract. Alkaloids and phenols present in this extract may be involved in the hypotensive effect.
\end{abstract}

Key Words: Blood pressure, hypotension, phytochemical compounds.

\section{INTRODUCTION}

Hypertension is a disease whose prevalence is consistent growth in all regions of the world. This disease has become a real public health problem (Whitworth et al., 2003, Kearney et al., 2004). The high cost of treatment and the inadequate specialized health center, encouraging many people in developing countries to use medicinal plants to treat this disease. Ficus exasperata is a species commonly used in the pharmacopoeia for the treatment of many diseases (Ahmed et al., 2012). Among the diseases treated include the hypertension. F. exasperata aqueous leaves extract reduced blood pressure (Adewole et al., 2011). The decreases of blood pressure induced by this extract were increased in dose-dependent (Ayinde et al., 2007). The hypotensive effect of aqueous leaf extract of $F$. exasperata is reduced in the presence of atropine and methylene blue (Amonkan et al., 2010.). The hypotensive effects of the leaves of $F$. exasperata were related to the cholinomimetic action of chemical compounds present in the extract. The aim of this work is to determine the active fraction and the chemical groups involved in the hypotensive effect of the extract. Thus, different fractions of the crude aqueous extract of leaves of $F$. exasperata were evaluated on blood pressure.

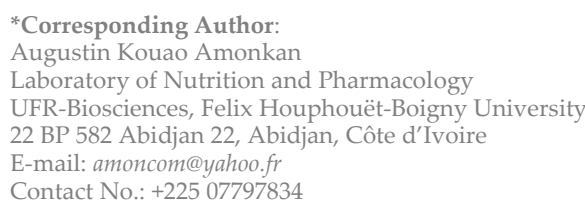

\section{MATERIALS AND METHODS}

\section{Ethics}

The experimental procedures and protocols used in this study were performed according to the recommendations of the Ethics Committee of Biological Sciences, University Félix Houphouët-Boigny. These guidelines were in accordance with the internationally accepted principles for laboratory animal use and care (National Research Council, 1996; Mosihuzzaman and Choudhary, 2008).

\section{Plant material}

The leaves of $F$. exasperata used for this study come from the southern region of the lagoons (Abidjan, Côte d'Ivoire.). The harvested organs were authenticated by Professor Ake-Assi at the National Center of Floristic (UFR Biosciences, University Felix Houphouet-Boigny, Abidjan, Côte d'Ivoire). A sample collected at Mount Tonkoui (Mountain region) by Professor Ake-Assi was preserved in the herbarium No. 3309.

\section{Fractional extraction of leaves of Ficus exasperata}

Fresh leaves were harvested, dried and pulverized. The resulting powder was macerated successively with hexane and distilled water according to the method described by Amonkan et al. (2013). The powder obtained after drying the extract in a rotary evaporator represents the crude aqueous extract of leaves of $F$. exasperata (FEFIX). FEFIX splitting was performed by successive maceration in solvents of different polarities at $5 \%$ under magnetic stirring for 24 hours. The filtrate obtained after FEFIX maceration in ethanol provided the ethanol fraction (FE-FEFIX). FEFIX filtrate obtained after maceration in methanol provided the methanol fraction (FM-FEFIX).

\section{Phytochemical tests}

The chemical compounds were detected by the reagents described by Petchi et al. (2013). Alkaloids detection was 


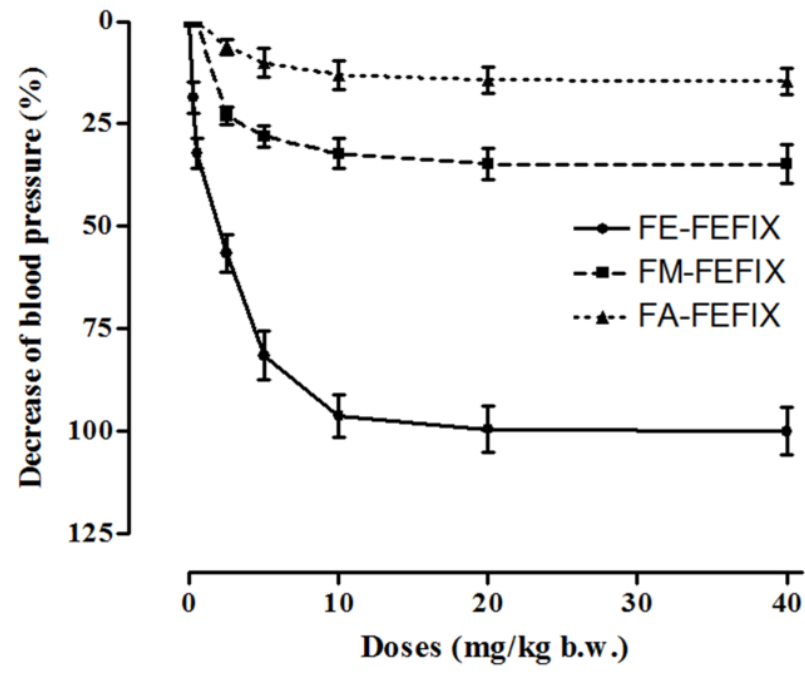

Figure 1: Effects of different fractions of crude aqueous extract of Ficus exasperata leaves on blood pressure in rabbits. Different doses of each fraction are administered intravenously and blood pressure is measured. Decreases in arterial pressure were expressed as percentages. FE-FEFIX: ethanolic fraction of $F$. exasperata leaves extract FM-FEFIX: methanolic fraction of $F$. exasperata leaves extract, FA-FEFIX: aqueous fraction of $F$. exasperata leaves extract.

performed using reagents Dragendorff and Valser-Mayer. Flavonoids were found through testing Chinoda. Gallic tannins and catechins were revealed by the ferric chloride solution and reagent Stiasny. The presence of quinones was highlighted by the reagent Borntraeger. Sterols and phenols were detected by the reagent Liebermann. The revelation of saponins was made by physical testing of the foam.

\section{Animal}

Male rabbits (Oryctolagus cuniculis) average weight of $2.7 \pm$ $0.3 \mathrm{~kg}$ was used for experimentation. Animals from farms of Bingerville (Abidjan, Côte d'Ivoire) were acclimated in the Biosciences animal house at the temperature $25 \pm 2{ }^{\circ} \mathrm{C}$, at least 14 days before the day of the experiment, with free access to food and water.

\section{Blood pressure measurement}

Different doses of FEFIX fractions were administered intravenously (saphenous vein intubated) to rabbits anesthetized with ethyl urethane $40 \%$ at a dose of $1 \mathrm{~g} / \mathrm{kg}$ b.w. Blood pressure was measured in the recording technique described by Nene Bi et al. (2008). Different doses of FEFIX fractions were prepared using a Mac Ewen solution.

\section{Drug and chemicals}

Extraction solvents used were ethanol (alcohol-Nadal, France) and methanol (Copechim Trading AG, Switzerland). Mac Ewen solution used has the following composition (mM): $\mathrm{NaCl}(130), \mathrm{KCl}(2.5), \mathrm{CaCl}_{2}$ (2.42), $\mathrm{Na}_{2} \mathrm{HPO}_{4}$ (1.18), $\mathrm{NaHCO}_{3}$ (11.90), $\mathrm{MgCl}_{2}$ (0.24), glucose (2.2). The salts used for the preparation of Mac Ewen from Sigma-Aldrich (France). The heparin was provides by Sanofi-Aventis (France).

\section{Statistical analysis}

The results were presented as mean with standard error of the mean (mean \pm sem) obtained from $n$ separate experi-

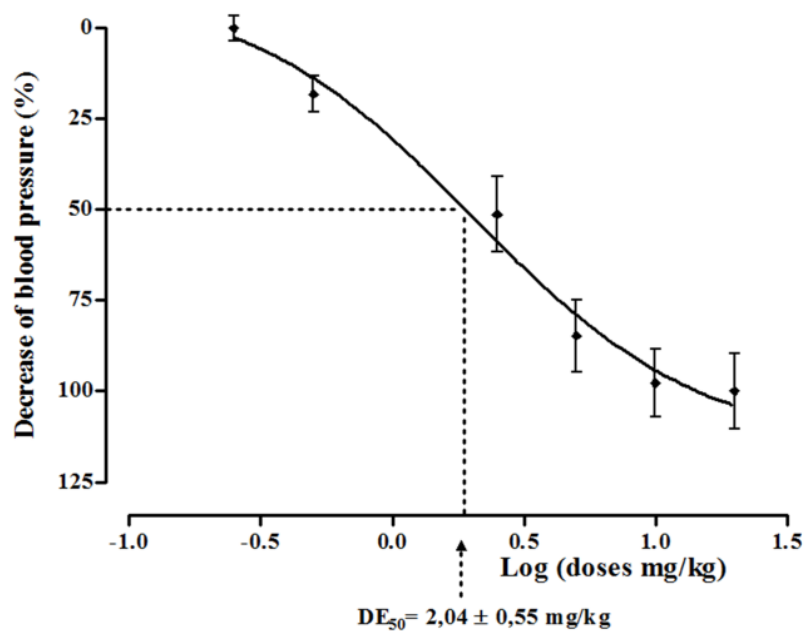

Figures 2: Effects of ethanol dose responses fraction of crude aqueous extract of leaves of Ficus exasperata on blood pressure and determination of the ED50. Increasing doses of the extract is administered intravenously and blood pressure is measured. The decrease in pressure was expressed as a percentage.

ments. Statistical analysis of the values and graphical representations of data were performed respectively by GraphPad Instat v3.00 software (Microsoft, San Diego, California, USA) and GraphPad Prism v4 software (Microsoft, San Diego, California, USA). Differences between the mean statistical validity are assessed through Tukey-Kramer multiple comparisons test. The difference between the averages is considered statistically significant at the $5 \%(\mathrm{p}<0.05)$.

\section{RESULTS}

\section{Phytochemical reports}

The phytochemical analysis showed that the chemical compounds present in the crude aqueous extract of leaves of Ficus exasperata (FEFIX) were divided according to the extraction solvent (table 1). Tannins and catechin saponins were present in the aqueous fraction (FA-FEFIX). Phenols and alkaloids were detected in the ethanolic fraction (FEFEFIX) and methanolic (FM-FEFIX) while flavonoids were only present in the methanolic fraction (FEFIX-FM).

\section{Effect of Ficus exasperata fractions}

The different fractions FEFIX decreased blood pressure (figure 1). The hypotension recorded differs depending on the fraction. The ethanol fraction decreased blood

Table 1: The phytochemical compounds present in the different fractions of the crude aqueous extract of Ficus exasperata leaves.

\begin{tabular}{cccc}
\hline Chemicals & FE-FEFIX & FM-FEFIX & FA-FEFIX \\
\hline Alkaloids & + & + & - \\
Flavonoids & - & + & + \\
Phenols & + & + & - \\
Quinones & - & - & - \\
Saponins & - & - & + \\
Polyterpenes and & - & - & - \\
Sterols & - & - & + \\
Catechin tannins & - & - & - \\
Gallic tannins & - & \\
\hline FE-FEFIX: ethanolic fraction of $F$. exasperata leaves extract FM-FEFIX: \\
methanolic fraction of $F$. exasperata leaves extract, FA-FEFIX: aqueous \\
fraction of $F$. exasperata leaves extract, +: positive test, - : negative test.
\end{tabular}


pressure from a dose of $0.25 \mathrm{mg} / \mathrm{kg}$ b.w. $(7.45 \pm 2.34 \mathrm{~mm}$ $\mathrm{Hg})$. While the hypotension induced by the other two fractions (FM-FEFIX and FA-FEFIX) are observed from the dose of $2.5 \mathrm{mg} / \mathrm{kg}$ b.w. with decreases in blood pressure of $5.25 \pm 182$ and $2.50 \pm 1.32 \mathrm{~mm} \mathrm{Hg}$ At a dose of $40 \mathrm{mg} / \mathrm{kg}$ b.w., the maximum hypotension were recorded for the three fractions, with decreases in blood pressure of $40.02 \pm 3.08 \mathrm{~mm} \mathrm{Hg}$ (FE-FEFIX), $8.95 \pm 1.09 \mathrm{~mm} \mathrm{Hg}$ (FMFEFIX) and $5.26 \pm 1.46 \mathrm{~mm} \mathrm{Hg}$ (FA-FEFIX). For doses ranging from 0.25 to $40 \mathrm{mg} / \mathrm{kg}$ b.w., the hypotension induced by FM-FEFIX and FA-FEFIX are relatively low $(\mathrm{P}>0.05)$, while those induced by FE-FEFIX are very important $(\mathrm{P}<0.001)$.

\section{Determination of ethanol fraction $\mathrm{ED}_{50}$}

Increasing doses of FE-FEFIX gradually decreased blood pressure (figure 2). The dose of $0.25 \mathrm{mg} / \mathrm{kg} \mathrm{b} . \mathrm{w}$. caused a decrease in blood pressure of $18.62 \pm 5.85 \%$. The maximum decrease $(100 \%)$ of blood pressure was obtained for the dose of $40 \mathrm{mg} / \mathrm{kg}$ b.w. The $50 \%$ effective dose (ED50) determined amounted to $2.04 \pm 0.55 \mathrm{mg} / \mathrm{kg}$ bw

\section{DISCUSSION}

The phytochemical screening of fractions of crude aqueous extract of $F$. exasperata leaves (FEFIX) reveals the presence of different chemical groups. These chemical compounds varied depending on the extraction solvent. The presence of different chemicals has been reported for the methanol extract of the bark, leaves and roots of $F$. exasperata. The extracts of these three organs contain tannins, flavonoids and saponins (Adebayo et al., 2009). In addition, ethanol extracts of leaves and bark of $F$. exasperata contained in addition to the above chemicals, alkaloids (Ijeh and Ukweni, 2007).

The fractions of the aqueous extract of $F$. exasperata reduce blood pressure. The hypotensive effect of the ethanolic fraction (FE-FEFIX) was larger than those of methanolic fractions (FM-FEFIX) and aqueous (FAFEFIX). ED50 of the FE-FEFIX is lower than that reported for the aqueous crude extract of leaves of $F$. exasperata (Amonkan et al., 2010). The hypotensive effect of the sheets resulted from the presence of alkaloids and phenols in the ethanolic fraction. The mesaconitine, an alkaloid extracted from the roots of Aconitum japonicum induced vasorelaxation which increases with the concentration of a preparation of gastric artery (Mitamura et al., 2002). The phytochemical analysis of the aqueous extract of Raphanus sativus revealed the presence of alkaloids, flavonoids, saponins, tannins and phenols. This extract reduced blood pressure by activation of muscarinic receptors (Ghayur and Giliani, 2006). Similar effects had also been reported for leaf extract Viola odorata which tested positive for alkaloids, saponins, tannins, flavonoids and phenols (Siddiqi et al., 2012).

\section{CONCLUSION}

The fractions of the crude aqueous extract of leaves of $F$. exasperata show differences in their phytochemical composition. The ethanol fraction mainly composed of alkaloids and phenols induced the greatest hypotensive effect. These chemicals compounds were involved in the hypotensive effect of the leaves of F. exasperata.

\section{ACKNOWLEDGEMENT}

The authors are sincerely grateful to Professors Yao Datté Jacques and Offoumou Atté Michel for their advice and guidance in the development of different protocols for this work.

\section{REFERENCES}

Adebayo, E. A., Ishola, O. R., Taiwo, O. S., Majolagbe, O. N. and Adekeye B. T. (2009). Evaluations of the methanol extract of Ficus exasperata stem bark, leaf and root for phytochemical analysis and antimicrobial activities. African Journal of Plant Science 3(12): 283-287.

Adewole, S. O., Ojo, S. K., Adenowo, T. K., Salako, A. A., Naicker, T. and Ojewole, J. A. (2012). Effects of Ficus exasperata vahl. (moraceae) leaf aqueous extract on the renal function of streptozotocin-treated rats. Folia Morphol (Warsz). 71(1): 1-9. PMID: 22532177.

Adewole, S.O., Adenowo, T., Naicker T. and Ojewole, J. A. (2011). Hypoglycaemic and hypotensive effects of Ficus exasperata vahl. (Moraceae) leaf aqueous extract in rats. Afr J Tradit Complement Altern Med. 8(3): 275-283. [DOI]

Ahmed, F., Mueen, A. K. K., Abedin, M. Z. and Karim, A. A. (2012). Traditional uses and pharmacological potential of Ficus exasperata vahl. Syst Rev Pharm. 3: 15-23. [DOI]

Amonkan, A. K., Konan, A. B., Ahui, B. M. L., Bleyere, M. N., Kouakou, L. K. and Bouafou, G. M. K. (2013). Diuretic Effects of Aqueous Extract of Ficus exasperata Vahl. Leaves in Rat. Pak. J. Biol. Sc. 16 (21): 1383-1387. [DOI]

Amonkan, K. A., Konan, A. B., Kouakou K. L., Bouafou K. G. M., Bléyéré, N. M., Ahui, M. L. B., Zannou, T. V., Ouattara, H., Datté, J. Y. and KatiCoulibaly, S. (2010) Phytochemical screening and effects of aqueous extract of Ficus exasperata Vahl. 1805 leaves (Moraceae) on blood pressure and contractile activity of the heart in mammals. Int J Biol Chem Sci. 4(3): 681-691. [DOI]

Ayinde, B. A., Omogbai, E. K., Amaechina, F. C. (2007). Pharmacognosy and hypotensive evaluation of Ficus exasperata Vahl (Moraceae) leaf. Acta Pol Pharm. 64(6):543-546. PMID: 18323249.

Ghayur, M. N. and Gilani A. H. (2006). Radish seed extract mediates it cardiovascular inhibitory effects via muscarinic receptor activation. Fundam Clin Pharmacol., 20(1): 57-63. [DOI]

Ijeh, I. I. and Ukweni, A. I. (2007). Acute effect of administration of ethano extracts of Ficus exasperata Vahl on kidney function in albino rats. J. Med. Plants Res. 1(2): 27-29.

Kearney, P. M., Whelton, M., Reynolds, K., Whelton, P. K. and He, J. (2004). Worldwide prevalence of hypertension: a systematic review. J Hypertens. 22(1): 11-19. [DOI]

Mitamura, M., Boussery, K., Horie, S., Murayama, T. and Van de Voorde, J. (2002). Vasorelaxing effect of mesaconitine, an alkaloid from Aconitum japonicum, on rat small gastric artery: possible involvement of endothelium-derived hyperpolarizing factor. Jpn J Pharmacol. 89(4): 380387. [DOI]

Mosihuzzaman, M. and Choudhary, M. I. (2008). Protocols on safety, efficacy, standardization and documentation of herbal medicine. Pure Appli. Chem. 80: 2195-2130. [DOI]

National Research Council. (1996). Guide for the Care and Use of Laboratory Animals. National Academy Press, Washington, DC., ISBN10: 0-309-05377-3.

Nene Bi, S. A, Traore, F, Zahoui, O. S. and Soro, T. Y. (2008). Phytochemical composition, pharmacological and toxicological studies of an aqueous extract of bridelia ferruginea benth. (euphorbiaceae) in mammalians. Afrique Science. 04(2): 287-305.

Petchi, R. R., Vijaya, C. and Parasuraman, S. (2013). Anti-arthritic activity of ethanolic extract of Tridax procumbens (Linn.) in Sprague Dawley rats. Pharmacognosy Res. 5(2): 113-117. [DOI]

Siddiqi, H. S., Mehmood, M. H., Rehman, N. U. and Gilani, A. H. (2012). Studies on the antihypertensive and antidyslipidemic activities of Viola odorata leaves extract. Lipids Health Dis., 11: 6. [DOI]

Whitworth, J. A., WHO and ISHWG. (2003). 2003 World Health Organization (WHO)/International Society of Hypertension (ISH) statement on management of hypertension. J Hypertens. 21(11):19831992. 